\title{
PELATIHAN SYUKUR UNTUK MENINGKATKAN SELF COMPASSION PADA CAREGIVER ANAK DENGAN DOWN SYNDROME
}

\section{GRATEFUL TRAINING TO INCREASE SELF COMPASSION AMONG CAREGIVERS OF CHILDREN WITH DOWN SYNDROME}

\author{
Ismi Zulaehah \\ Sri Kushartati \\ Fakultas Psikologi Universitas Ahmad Dahlan Yogyakarta \\ Email: ismizulaehah@gmail.com; srikus13@gmail.com
}

\begin{abstract}
This study aims to explain the effect of grateful training in order to increase self compassion among caregivers of children with down syndrome. Caregivers who get gratitude training were expected to have higher score at self compassion scale than the caregivers who did not get the treatment. The subjects of this study were seven adult caregivers of children with down syndrome, Muslim, female. They could be parents or closest relatives of children with down syndrome. The children with down syndrome were students of SLB PGRI Trimulyo. The kind of this research was pre-experimental with single pre-post test design. The collecting data used self compassion scale and it was analyzed by using Wilcoxon test. The hypothesis of this study was that gratitude training can increase self compassion among caregivers of children with down syndrome. The result of the study shows that there is significantly difference self compassion between before and after treatment was given. This proves that gratitude training can increase self compassion of caregivers of children with down syndrome.
\end{abstract}

Keywords: caregivers, down syndrome, gratitude training, self compassion.

\begin{abstract}
ABSTRAK
Penelitian ini bertujuan untuk dapat meningkatkan self compassion pada caregiver anak dengan down syndrome melalui pelatihan syukur. Caregiver yang mendapatkan pelatihan ini diharapkan memiliki self compassion yang lebih tinggi dibandingkan dengan caregiver yang tidak mendapatkan pelatihan syukur. Subjek dari penelitian yaitu caregiver anak dengan down syndrome sebanyak tujuh orang dewasa, beragama Islam, jenis kelamin perempuan, merupakan orangtua atau keluarga terdekat anak dengan down syndrome yang merupakan siswa SLB PGRI Trimulyo. Jenis penelitian yang digunakan adalah penelitian pre eksperimen dengan desain eksperimen single pre-post test design. Metode pengumpulan data dalam penelitian ini mengunakan skala self compassion dan dianalisis menggunakan uji Wilcoxon. Hipotesis yang diajukan dalam penelitian ini adalah pelatihan syukur dapat meningkatkan self compassion pada caregiver anak dengan down syndrome. Hasil penelitian menunjukan bahwa terdapat perbedaan self compassion yang signifikan antara sebelum dan setelah pelatihan. Hal ini membuktikan bahwa pelatihan syukur dapat meningkatkan self compassion pada caregiver anak dengan down syndrome.
\end{abstract}

Kata kunci : caregiver anak dengan down syndrome, pelatihan syukur, self compassion. 
Menghadapi suatu kegagalan atau persoalan dalam hidup, diperlukan sikap penerimaan diri. Penerimaan diri tersebut penting agar individu tidak mengalami hambatan psikologis. Salah satu faktor yang berperan penting membantu individu mampu menerima diri ketika menghadapi suatu persoalan adalah self compassion. Neff (2003) menjelaskan bahwa self compassion adalah proses pemahaman tanpa kritik terhadap penderitaan, kegagalan atau ketidakmampuan diri dengan cara memahami bahwa ketiga hal tersebut merupakan bagian dari pengalaman sebagai manusia pada umumnya.

Begitu banyak manfaat yang dapat diperoleh jika seseorang memiliki self compassion yang tinggi. Beberapa di antaranya adalah memiliki tingkat kecemasan dan depresi lebih rendah daripada individu yang memiliki tingkat self compassion rendah (Neff, 2009). Selain itu menjadikan individu memiliki inisiatif dalam hidup mereka serta memiliki keinginan untuk mencapai potensi penuh yang dimiliki (Neff, Rude, \& Kirkpatrick, 2007). Tingkat kecemasan dan perilaku self-handicapping seperti penundaan terhadap tugas Individu yang memiliki self compassion adalah rendah dibandingkan individu yang tidak memiliki self compassion (Williams, Stark, \& Foster, 2008). Neff dkk (2005) melengkapi bahwa self compassion berhubungan positif dengan tujuan dan motivasi intrinsik untuk belajar dan tumbuh. Dengan demikian, selfcompassion membuat individu memiliki motivasi yang tinggi untuk sukses.

Berdasarkan peran penting tersebut, self compassion sudah sewajarnya menjadi bagian dari diri tiap individu, khususnya adalah orang tua yang memiliki anak berkebutuhan khusus seperti down syndrome. Prevalensi down syndrome kira-kira 1 berbanding 700 kelahiran. Di dunia, lebih kurang ada 8 juta anak down syndrome. Di Indonesia, dari hasil survei terbaru, sudah mencapai lebih dari 300.000 orang. (Jakarta, kompas. com 29 Maret 2011).

Menurut Papalia, Olds, dan Feldman (2009), down syndrome merupakan suatu kelainan kromosom, yang pada umumnya terjadi karena adanya kromosom tambahan pada kromosom ke 21. Selain itu, Mumpuniarti (2007) juga menjelaskan bahwa down syndrome merupakan salah satu klasifikasi tunagrahita berdasarkan tipe klinis/fisik. Tunagrahita adalah istilah yang digunakan untuk menyebut anak yang mempunyai kemampuan intelektual di bawah rata-rata (Somantri, 2006). Keadaan seperti itu, anak dengan down syndrome tetaplah merupakan makhluk sosial yang membutuhkan dukungan dari lingkungan sosialnya, terutama dari orangtua yang menjadi caregiver bagi mereka. 
Caregiver adalah seseorang, baik yang dibayar ataupun secara sukarela, bersedia memberikan perawatan kepada orang lain yang memiliki masalah kesehatan dan keterbatasan dalam merawat dirinya sendiri, bantuan tersebut meliputi bantuan untuk kehidupan seharihari, perawatan kesehatan, finansial, bimbingan, persahabatan serta interaksi sosial (Schulz \& Quittner, 1998; Swanson dkk, 2009). Tidaklah mudah bagi caregiver untuk merawat anak dengan down syndrome dengan segala keterbatasannya, dibutuhkan ketelaten-an, keikhlasan dan kesabaran. Hal ini berhubungan dengan self compassion yang dimiliki caregiver. Caregiver seharusnya memiliki self compassion yang tinggi agar dapat merawat anak dengan down syndrome dengan baik.

Berdasarkan wawancara pada guru SLB PGRI Trimulyo, ditemukan bahwa beberapa caregiver anak dengan down syndrome memiliki self compassion yang rendah karena belum memenuhi tiga komponen self compassion menurut Neff (2003b) yaitu self-kindness, common humanity, dan mindfulnes. Pertama: selfkindness. Self-kindness adalah kemampuan individu untuk memahami diri sendiri dan menerima apa adanya serta memaknai kegagalan yang dihadapi, tanpa menyakiti atau menghakimi diri sendiri. Kedua: Common humanity. Common humanity adalah pemahaman secara lebih luas tentang peristiwa baik atau buruk yang dialami sebagai peristiwa yang umum dialami oleh manusia. Ketiga: Mindfulness. Mindfulness adalah melihat dan menerima kenyataan yang terjadi dalam hidup secara objektif dan menghadapi kenyataan tersebut tanpa adanya kritik atau menghakimi diri sendiri.

Dari hasil wawancara, ditemukan bahwa salah satu komponen yang belum dipenuhi oleh caregiver adalah komponen mindfulness yaitu caregiver tidak mampu melihat keadaan anak secara objektif (Neff, 2003), caregiver cenderung melebih-lebihkan keterbatasan pada anak sehingga tidak memberikan kesempatan anak untuk berkembang.

Berbeda dengan hasil survey yang dilakukan oleh Dr. Brian Skotko dari Children's Hospital Boston seperti yang dilansir Healthday, Minggu (2/10/2011), menyatakan bahwa keluarga yang memiliki anak dengan down syndrome tidak merasa putus asa, mereka justru merasa menjadi lebih baik, lebih bahagia dan hal tersebut mengajarkan kesabaran, keluwesan, penerimaan dan menjadikan dorongan bagi keluarga untuk meningkatkan kualitas hidupnya. Dari data tersebut, dapat disimpulkan bahwa sebenarnya caregiver anak dengan down syndrome juga dapat memiliki self compassion yang tinggi, begitu pun dengan caregiver anak dengan down syndrome yang merupakan orangtua dari siswa SLB PGRI Trimulyo. 
Self compassion muncul karena adanya faktor-faktor. Pertama: Jenis Kelamin Penelitian menunjukkan bahwa wanita memiliki lebih banyak pemikiran dibandingkan laki-laki, sehingga perempuan menderita depresi dan kecemasan dua kali lipat dibandingkan pria (Neff, 2011). Hal ini dikarenakan oleh tabiat perempuan yang memikirkan mengenai kejadian negatif masa lalu dan cenderung lebih sering mengkritik diri sendiri. Penjelasan tersebut diperkuat oleh hasil penelitian Akin (2010) yang menunjukkan bahwa perempuan memiliki self compassion yang lebih rendah dibanding degan laki-laki.

Kedua: Usia. Ada beberapa penelitian yang menyebutkan bahwa usia mempunyai hubungan yang signifikan dengan tingkat self compassion seseorang (Neff \& Vonk, 2009). Neff dan Vonk menganalisis berdasarkan teori perkembangan Erickson. Teori tersebut menyatakan bahwa orang-orang yang telah mencapai tahap integrity dapat memiliki self compassion yang lebih tinggi. Hal ini dikarenakan pada tahap ini mereka akan lebih menerima kondisi yang dialami. Menurut Erikson, tahapan perkembangan integrity dicirikan dengan seseorang yang dapat menerima dirinya secara positif.

Ketiga: Kecerdasan Emosi. Neff (2009) menyatakan bahwa self compassion berhubungan erat dengan kecerdasan emosional dan kebijaksanaan. Maslow
(1968) dalam "Toward Psychology of Being" memaparkan bahwa munculnya penerimaan dengan kasih sayang, tanpa penilaian, dan penuh maaf pada diri sendiri maupun orang lain, semua ini dipengaruhi oleh kematangan emosi. Penerimaan diri merupakan salah satu bentuk atau komponen dari self compassion.

Keempat: Kepribadian. The Big Five Personality merupakan dimensi dari kepribadian (personality) yang dipakai untuk menggambarkan kepribadian individu. Berdasarkan pengukuran yang dilakukan oleh NEO-FFI, ditemukan bahwa self-compassion memiliki hubungan dengan dimensi neuroticism, agreebleness, extroversion, dan conscientiousness dari the big five personality. Namun, self-compassion tidak memiliki hubungan dengan openness to experience, karena trait ini mengukur karakteristik individu yang memiliki imajinasi yang aktif, kepekaan secara aesthetic, sehingga dimensi openness to experience ini tidak sesuai dengan self-compassion (Neff, 2007). Dapat disimpulkan bahwa kepribadian seseorang dapat mempengaruhi tingkat self compassion yang dimilkinya

Kelima: Budaya. Hasil penelitian yang dilakukan di negara Thailand, Taiwan, dan Amerika Serikat menunjukkan bahwa perbedaan latar belakang budaya ketiga negara tersebut mengakibatkan adanya perbedaan derajat self com- 
passion. Self compassion tertinggi terdapat di Thailand dan terendah di Taiwan. Markus dan Kitayama (1991) dalam Neff, Pisitsungkagarn, Hsieh (2008) mengatakan bahwa orang-orang Asia memiliki budaya collectivistic yang dikatakan memiliki self-concept interedependent yang menekankan pada pentingnya bersosialisasi dengan orang lain, peduli kepada orang lain, dan keseimbangan dengan orang lain dalam bertingkah laku, sedangkan individu dengan budaya Barat yang individualistic memiliki self-concept independent yang menekankan pada kemandirian, kebutuhan pribadi, dan keunikan individu dalam bertingkah laku.

Dalam self compassion terdapat common hummanity yang menekankan pada perasaan kebersamaan dengan yang lain yang mengasumsikan bahwa orang yang berhubungan luas dengan orang lain adalah orang yang memiliki self compassion yang lebih tinggi. Ini berarti bahwa orang Asia memilki self compassion lebih tinggi daripada orang barat, namun karena orang Asia lebih cenderung mengkritik diri sendiri maka dari hasil penelitian terdahulu self compassion orang Barat lebih tinggi daripada self compassion orang Asia (Kitayama \& Markus, 2000; Kitayama, Markus, Matsumotoo, \& Norasakkunkit, 1997).

Keenam: Peran orang tua. Keluarga merupakan lingkungan pendidikan perta- ma bagi anak, semua yang diajarkan orangtua maupun anggota keluarga yang lain akan melekat pada diri anak. Oleh karena itu, peran orangtua atau anggota keluarga terdekat akan mempengaruhi tingkat self compassion yang dimiliki.

Anak beranggapan bahwa orangtua merupakan orang yang bisa membuat nyaman anak dan bisa membimbing anak dengan baik. Namun, terdapat beberapa orangtua yang berusaha untuk mengontrol anak dengan selalu mengkritik anak. Anak-anak dari usia dini yang sudah terbiasa tumbuh dengan kritikan, akan memiliki derajat self-compassion yang rendah. Hal ini dikarenakan ketika dewasa akan menjadi orang yang lebih sering mengkritik diri sendiri.

Selain itu, penerimaan dari orangtua sangat penting bagi penerimaan anak terhadap diri sendiri. Ketika orang tua mampu menerima individu dengan baik maka individu akan menerima diri sendiri dengan baik pula, begitupun sebaliknya. $\mathrm{Hal}$ ini berhubungan dengan komponen self compassion yang pertama yaitu self kindness (Eaves, 2007).

Model dari orangtua juga dapat mempengaruhi self-compassion yang dimiliki individu, yaitu contoh perilaku orangtua yang sering mengkritik diri sendiri saat menghadapi kegagalan atau kesulitan. Orangtua yang mengkritik diri akan menjadi contoh bagi individu untuk melakukan hal tersebut saat mengalami 
kegagalan yang menunjukkan derajat selfcompassion yang rendah.

Dapat disimpulkan bahwa faktorfaktor yang dapat mempengaruhi self compassion pada diri individu yaitu jenis kelamin, usia, kecerdasan emosi, kepribadian, budaya dan peran keluarga.

Untuk meningkatkan self compassion pada caregiver, peneliti mengusulkan salah satu cara yaitu melalui pendekatan agama. American Psychiatric Association (Hawari, 2004) menjelaskan pentingnya agama dalam kesehatan yang dapat dilihat dari Batasan organisasi Kesehatan Dunia (WHO) (Hawari, 2004) bahwa ciri agama (spiritual) merupakan salah satu unsur dari pengertian kesehatan seutuhnya. Dalam penelitian Chrisnawati (2008), didapatkan hasil bahwa religiusitas dapat meningkatkan kecerdasan emosional seseorang. Kecerdasan emosional merupakan salah satu faktor yang dapat meningkatkan self compassion dari beberapa faktor lainnya yaitu: jenis kelamin (Neff, 2011), usia (Neff \& Vonk, 2009), kecerdasan emosi (Neff, 2009), personality (Neff, 2007), budaya (Neff, Pisitsungkagarn, Hsieh, 2008). Kemudian religiusitas diaplikasikan melalui pelatihan syukur.

Martoyo (1996) menyatakan bahwa pelatihan adalah suatu proses pendidikan jangka pendek yang menggunakan prosedur sistematis dan teroganisir. Emmons dan McCullough (2003) menunjukkan bahwa syukur merupakan sebuah bentuk emosi atau perasaan, yang kemudian berkembang menjadi suatu sikap, sifat moral yang baik, kebiasaan, sifat kepribadian, dan akhirnya akan mempengaruhi seseorang menanggapi/bereaksi terhadap sesuatu atau situasi.

Oleh karena itu dapat disimpulkan bahwa pelatihan syukur adalah proses pendidikan penerimaan atas apa yang terjadi. Proses yang telah direncanakan dan terstruktur dalam melatih caregiver untuk bersyukur agar self compassion yang dimiliki dapat meningkat. Pelatihan syukur yang akan diberikan dalam penelitian ini adalah pelatihan syukur Islami, yaitu menyajikan tahapan pem-biasan syukur menurut Emmons (2007) dan dipadukan dengan syukur Islam menurut Ghazali (2011).

Hipotesis yang diajukan adalah bahwa pelatihan syukur dapat meningkatkan self compassion pada caregiver anak dengan down syndrome. Tujuan dalam penelitian ini adalah untuk mengetahui apakah pelatihan syukur dapat meningkatkan self compassion pada caregiver anak dengan down syndrome.

\section{METODE PENELITIAN}

\section{Desain Penelitian}

Jenis penelitian yang digunakan adalah penelitian pra-eksperimen, penentuan sampel dengan menggunakan metode purposive sampling dengan 
desain eksperimen single pre-post-follow up test design. Penelitian akan dilakukan hanya pada kelompok eksperimen tanpa kelompok kontrol. Penelitian pra-eksperimen dilakukan untuk meneliti kemungkinan adanya pengaruh variabel independent terhadap variabel dependent. Hal ini dilakukan dengan cara menghadapkan kelompok eksperimen dengan perlakuan dan membandingkan hasil antara sebelum dan sesudah diberikan perlakuan (Azwar, 2007).

\section{Subjek Penelitian}

Subjek dalam penelitian yaitu caregiver anak dengan down syndrome sebanyak tujuh orang dewasa, beragama Islam, jenis kelamin perempuan, dan merupakan orangtua atau keluarga terdekat anak dengan down syndrome yang merupakan siswa SLB PGRI Trimulyo.

\section{Metode Pengumpulan Data}

Penelitian ini bertujuan untuk dapat meningkatkan self compassion pada caregiver anak dengan down syndrome melalui pelatihan syukur. Caregiver yang mendapatkan pelatihan ini diharapkan memiliki self compassion yang lebih tinggi dibandingkan dengan caregiver yang tidak mendapatkan pelatihan syukur.

Self compassion merupakan kesediaan diri untuk memahami dengan baik bahwa suatu kegagalan atau ketidak- mampuan diri merupakan bagian dari hidup manusia pada umumnya. Alat yang digunakan untuk melihat self compassion subjek adalah skala self compassion. Skala diambil dari teori Neff yang telah diadaptasi ke dalam bahasa Indonesia oleh Rias (2014). Skala tersebut terdiri dari tiga komponen utama yaitu self kindness, common humanity dan mindfulness. Aitem pernyataan dengan sistem skala summated rating methods dengan menggunakan lima pilihan alternatif respon skala. Jika skor yang diperoleh subjek dari skala yang diberikan itu tinggi, berarti subjek memiliki self compassion yang tinggi. Begitupun sebaliknya, subjek yang memperoleh skor rendah berarti memiliki self compassion yang rendah.

\section{Prosedur Intervensi}

Pelatihan syukur dalam penelitian ini menggunakan pelatihan syukur Islam. Modul merujuk pada modul pelatihan yang telah dilakukan oleh Emmons (2007) yang kemudian disesuaikan dengan syukur dalam Islam. Pelatihan syukur Islam ini terdiri dari pengetahuan tentang syukur, yang berisi pengetahuan tentang nikmat, sumber nikmat, sifat Sang pemberi nikmat (Allah) dan pengetahuan tentang syukur dalam Islam, selanjutnya bersyukur pada hal-hal sederhana, membuat buku harian syukur, mengingat peristiwa sulit dan melihat keadaan orangorang yang kurang beruntung, berpikir out 
of the box, do'a bersyukur, membuat komitmen atau janji untuk selalu bersyukur, membuat surat syukur, refleksi diri (muhasabah), menjaga perkataan dan membuat pengingat syukur. Pelatihan ini menggunakan modul pada penelitian sebelumnya oleh Arikawati (2013) dan telah mendapat persetujuan langsung oleh Arikawati. Pelatihan syukur akan diberikan sebanyak tiga kali pertemuan dengan jumlah sesi yang bervariasi di setiap pertemuan. Pertemuan pertama terdapat lima sesi yang berlangsung selama 140 menit, pertemuan kedua

terdapat lima sesi dalam waktu 140 menit, dan pertemuan terakhir sembilan sesi dalam waktu 145 menit.

\section{Teknik Analisis Data}

Metode pengumpulan data dalam penelitian ini menggunakan skala self compassion dan dianalisis menggunakan uji wilcoxon.

\section{HASIL PENELITIAN}

\section{Deskripsi Data}

Tabel 1. Skor Prates dan Pascates Subjek

\begin{tabular}{lllll}
\hline \multirow{2}{*}{ No } & \multirow{2}{*}{ Subjek } & \multicolumn{3}{c}{ Skor } \\
\cline { 3 - 5 } & & Pre test & Post test & Follow up \\
\hline 1. & NTJ & 106 & 103 & 108 \\
2. & NTI & 90 & 99 & 111 \\
3. & SP & 101 & 100 & 115 \\
4. & MA & 85 & 88 & 110 \\
5. & JRY & 90 & 80 & 105 \\
6. & SPR & 79 & 102 & 92 \\
7. & SRY & 99 & 107 & 129 \\
\hline SPSS & Z & & & $-2,366$ \\
& & $-0,762$ & $-2,032$ & 0,01 \\
\hline
\end{tabular}

\section{Hasil Analisis Data}

Hasil uji wilcoxon pada penelitian menunjukkan bahwa $Z$ score pada saat pre test dan post test sebesar $-0,762$ dengan $p=0,446 \quad(p>0,05), \quad$ maka hipotesis ditolak, dengan kata lain tidak ada perbedaan tingkat self compassion antara skor pre test dan post test. Hal ini dikarenakan saat subjek mengisi skala pada post test, subjek mengaku sudah kelelahan karena materi pada pertemuan ketiga lebih banyak daripada pertemuan sebelumnya, tugas pun lebih banyak dari sebelumnya. Selain itu adalah karena 
subjek tidak tenang karena waktu sudah menunjukkan waktu pulang sekolah anak, subjek khawatir jika anak mereka pulang tetapi tidak bertemu dengan mereka, maka anak akan menangis atau pulang sendiri.

Hasil uji Wilcoxon post test dan follow up menunjukan $Z$ score sebesar 2,032 dengan $p=0,042(p<0,05)$, maka hipotesis diterima, dengan kata lain terdapat perbedaan tingkat self compassion yang signifikan antara skor post test dan follow up. Saat dilakukan follow up, subjek lebih tenang dalam mengisi pernyataan dalam skala, berbeda dengan ketika mengisi skala post test. Saat mengisi skala, subjek banyak bercerita tentang perubahan yang dialaminya setelah mengikuti pelatihan. Subjek merasa bersyukur karena telah mengikuti pelatihan.

Terakhir pada skor pre test dan follow up menunjukan Z score sebesar 2,366 dengan $p=0,018(p<0,05)$, maka hipotesis diterima, dengan kata lain terdapat perbedaan tingkat self compassion yang signifikan antara skor pre test dan follow up. Hal ini disebabkan saat subjek mengisi skala self compassion, subjek belum mendapatkan pelatihan syukur, sedangkan saat follow up subjek telah mendapatkan seluruh rangkaian pelatihan syukur dan sudah menyerap isi dari pelatihan syukur tersebut. Hal ini diketahui melalui pengakuan subjek yang merasa menjadi lebih baik dan lebih sabar setelah mengikuti pelatihan syukur.

\section{PEMBAHASAN}

Subjek dapat meningkatkan self compassion melalui sepuluh tahap pembiasaan syukur yang sudah diberikan selama pelatihan. Setiap tahapan memiliki pengaruh terhadap komponen self compassion yang terdapat pada subjek. Hal ini terlihat dari perubahan yang terjadi pada subjek setiap selesai diberikan satu tahapan. Pada setiap sesi, fasilitator selalu menanyakan pemahaman subjek dan kemudian meminta subjek untuk dapat mengembangkannya lagi. Subjek bercerita mengenai keadaan dirinya sebelum dan sesudah mendapatkan materi pada setiap sesi pelatihan. Hasil yang didapatkan adalah setelah selesai sesi dalam pelatihan, terjadi perubahan ke arah yang lebih baik dari keadaan subjek sebelumnya sehingga dapat mempengaruhi komponen self compassion, yang kemudian juga akan meningkatkan self compassion subjek.

Subjek memerlukan waktu untuk menyerap dan memahami materi yang telah disampaikan selama pelatihan sehingga dapat meningkatkan kesyukuran subjek terhadap nikmat yang diberikan, kemudian subjek dapat meningkatkan self compassion mereka. Pada saat pre test, subjek masih mengeluhkan keadaan yang 
terjadi dalam hidupnya, salah satunya adalah mengeluhkan masalah anak. Terdapat subjek yang masih mengatakan anaknya "ngeyel, nakal, susah diatur, tidak bisa mandiri," subjek mengatakan hal seperti itu sambil melihat teman yang lain kemudian meminta saran dari fasilitator bagaimana harus menghadapi dan mendidik anaknya. Hal ini menunjukkan bahwa subjek masih belum bisa menerima keadaan anaknya. Kemudian saat post test, subjek bercerita mulai mampu mengenal nikmat-nikmat yang diterima dari Allah dan telah mampu disyukurinya, kemudian sudah tidak ada subjek yang mengatakan anaknya seperti yang telah dijelaskan di atas, namun subjek masih bertanya bagaimana seharusnya menghadapi dan mendidik anak agar bisa menjadi lebih baik lagi. Terakhir adalah ketika follow up, peneliti melakukan wawancara singkat dengan subjek, rata-rata subjek mengatakan senang dengan pelatihan syukur yang diberikan, karena dapat menjadikan subjek dapat bersyukur atas segala yang terjadi di dalam hidupnya. Sebelumnya subjek sering mengeluh atas apa yang terjadi dalam hidupnya, kurang menyadari nikmat yang diberikan Allah sehingga tidak dapat mensyukurinya. Namun setelah diberikan pelatihan ini, subjek merasa lebih bahagia karena dapat menyadari nikmat dari Allah dan dapat mensyukurinya. Khususnya subjek lebih mensyukuri keistimewaan yang dimiliki oleh anak mereka, yang sebelumnya kadang mengeluh karena anak mereka berbeda dengan anak yang lainnya. Setelah pelatihan, subjek mengatakan bahwa subjek mengetahui harus menyikapi anak mereka seperti apa. Dengan meningkatnya syukur yang dimiliki subjek, dapat meningkatkan self compassion yang mereka miliki, dapat dilihat berdasarkan analisis kuantitatif yang telah dilakukan.

Berdasarkan hasil analisis data menggunakan uji wilcoxon dan wawancara singkat, dapat disimpulkan bahwa terdapat perbedaan yang signifikan pada self compassion caregiver sebelum dan setelah diberikan perlakuan berupa pelatihan syukur. Hal ini mendukung teori Emmons dan McCullough (2003) bahwa syukur merupakan sebuah bentuk emosi atau perasaan, yang kemudian berkembang menjadi suatu sikap, sifat moral yang baik, kebiasaan, sifat kepribadian, dan akhirnya akan mempengaruhi seseorang menanggapi/bereaksi terhadap sesuatu atau situasi. Oleh karena itu dapat disimpulkan bahwa hipotesis penelitian ini diterima, yaitu pelatihan syukur dapat meningkatkan self compassion pada caregiver anak dengan down syndrome. 


\section{SIMPULAN DAN SARAN}

\section{Simpulan}

Berdasarkan hasil penelitian dan pembahasan, dapat disimpulkan bahwa intervensi berupa pelatihan syukur dapat meningkatkan self compassion pada caregiver anak dengan down syndrome, hal ini berdasarkan analisis data menggunakan analisis statistik non-parametrik yaitu dengan uji peringkat bertanda Wilcoxon. Berdasarkan hasil follow-up dapat dilihat bahwa subjek mampu mempertahankan efek dari pelatihan syukur selama lima hari setelah post-test. Hal ini berarti bahwa pelatihan syukur berhasil meningkatkan self compassion subjek dan subjek dapat mempertahankannya setelah pelatihan tidak dilakukan lagi.

Berdasarkan hasil wawancara singkat yang dilakukan kepada semua subjek, semua subjek mengaku bahwa pelatihan syukur menjadikan subjek lebih dekat dengan Allah, lebih menyadari nikmat dari Allah sehingga membuat subjek dapat mensyukuri setiap nikmat yang diberikan. Efek dari perasaan syukur menjadikan subjek menjadi pribadi yang lebih baik lagi, lebih menerima yang terjadi dalam hidupnya, lebih menerima kondisi anak dengan down syndrome yang mereka miliki berikut dengan cara menghadapinya. Selain itu subjek merasa lebih baik kepada diri sendiri dan orang lain serta lebih sabar.

\section{Saran}

Bagi peneliti selanjutnya yang ingin menggunakan modul yang sama, maka disarankan untuk dapat mengembangkan modul sesuai dengan subjek yang akan diberikan perlakuan. Hal-hal yang harus diperhatikan dalam modul adalah durasi penelitian, karena waktu yang sedikit akan mempengaruhi kualitas materi yang dipahami oleh subjek. Selain itu adalah pemberian tugas, karena penugasan yang kurang tepat akan mempengaruhi manfaaat dari intervensi yang diberikan.

Selain itu, agar lebih mudah untuk mengetahui lebih dalam kondisi subjek serta melakukan evaluasi, peneliti sebaiknya menyediakan waktu khusus untuk sharing. Penggunaan bahasa dalam skala sebaiknya disesuaikan dengan latar belakang subjek.

\section{DAFTAR PUSTAKA}

Al-Ghazali, I.A.H. (2011). Ihya' ulumuddin. Menghidupkan Ilmuilmu agama. Bandung: Penerbit Marja.

Arikawati, Y. (2013). Pelatihan bersyukur Islam untuk meningkatkan kesejahteraan subjektif pada remaja panti asuhan. Tesis. Yogyakarta: Program pascasarjana Magister 
Psikologi Universitas Ahmad Dahlan.

Azwar, S. (2003). Penyusunan skala psikologi. Yogyakarta: Pustaka Pelajar.

Chrisnawati, A.F.I. (2008). Hubungan antara religiusitas dengan kecerdasan emosional pada mahasiswa papua. Skripsi. Semarang: Fakultas Psikologi Universitas Katolik Soegijapranata.

Emmons, R. A. \& McCullough, M. E. (2003). Counting blessings versus burdens: an experimental investigation of gratitude and subjec-tive well-being in daily life. Journal of personallity and Social Psycho-logy, 84, 1-13.

Emmons, R. A. (2007). Thank's! How the new science of gratitude can make you happier. New York: Houghton Mifflin Company.

Harnowo, P.A. (2011). Detik health minggu, 02/10/2011 12:02 WIB. http://health.detik.com/read/2011/1 0/02/120255/1734833/763/meskipunya-anak-down-syndromekeluarga-merasa-bahagia. Diakses 27 Maret 2015.

Hawari, D (2004). Al-Quran: Ilmu kedokteran jiwa dan kesehatan jiwa. Yogyakarta: Dana Bhakti Prima Yasa.
Lusia, K. (2010), Teori baru penyebab down syndrome, 29 Maret 2010, Kompas.com Health, http://health. kompas.com/read/2010/03/29/111 91896/www.kompas.com. Diakses 27 Maret 2015.

Mangunsong, F. (2011). Psikologi dan pendidikan anak luar biasa. Jilid 1. LPSP3. Jakarta.

Martoyo. (1996). Manajemen sumber daya manusia. Yogyakarta: BPFE.

Mumpuniarti. (2007). Pembelajaran akademik bagi tunagrahita. Yogyakarta: Fakultas Ilmu Pendidikan UNY.

Neff, K. (2003). Self-compassion: An alternative conceptualization of a healthy attitude toward oneself. Self and Identity, 2, 85-101.

Neff, K. D., Hseih, Y., \& Dejitthirat, K. (2005). Self-compassion, achievement goals, and coping with academic failure. Self and Identity, 4, 263-287. 63.

Neff, K. D. (2009). Self-Compassion. In M. R. Leary \& R. H. Hoyle (Eds.), Handbook of Individual Differences in Social Behavior (pp. 561-573). New York: Guilford Press.

Neff, K., Kirkpatrick, K. L., \& Rude, S. S. (2007). Self-compassion and adaptive psychological functioning 
Journal of Research in Per-sonality, 41, 139-154.

Neff, K., Pisitsungkagarn, K., \& Hsieh, Y. P. (2008). Self-compassion and selfconstrual in the United States, Thailand, and Taiwan. Journal of Cross-Cultural Psychology, 39, 267285.

Papalia, D.E., Old, S.W., \& Feldman, R.D. (2009). Perkembangan manusia edisi 10. (Terjemahan: Brian Marswendy). Jakarta: Salemba Humanika.

Rias, M. (2014). Self-Compassion dan compassion for others pada mahasiswa fakultas psikologi UK. Maranatha. Bandung: Fakultas
Psikologi Universitas Kristen
Maranatha.

Schulz, R \& Quittner, A.R. (1998). Caregiving for children and adults with chronic conditions: Introduction to the special issue. Health Psychology, 17(2),107-111.

Somantri, A. (2006). Aplikasi statistika dalam penelitian. Bandung: Pustaka Setia.

Williams, J.G., Stark, S.K., \& Foster, E.E. (2008). Start today or the very last day? The relationships among selfcompassion, motivation, and procrastination. American Journal Of Psychological Research, 4, 1 